\title{
KAJIAN HUKUM DAN IMPLEMENTASI WAKAF HARTA BERGERAK DI INDONESIA: WAKAF UANG DAN SAHAM
}

\author{
Girindra Mega Paksi, Asfi Manzilati, Marlina Ekawaty \\ Fakultas Ekonomi dan Bisnis Universitas Brawijaya \\ E-mail:gmpaksi@gmail.com
}

\begin{abstract}
The Implementation and Legality Review of Movable Treasure Endowments in Indonesia: Endowments of Money and Shares. Endowment or Waqf is a non-market wealth distribution methods alongside zakah, infaq, and sadaqa. Particularly in Indonesia, waqf practice is identical with fixed asset donation notably land and building. The utilization of most waqf asset in Indonesia is not economically productive, such as mosque and cemetery. The aims of this study are to analyze the precept of cash and share waqf and its implementations. This study is classified as a literature review with qualitative approach. A Meta-synthesis method is applied as analyzing tools. Results shows that most Islamic scholar allow cash and shares to be used as waqf object. Both cash and share waqf can be implemented into two models. Cash waqf can be implemented as mutual fund or converted into other fixed asset. While share waqf implementation can be done through corporate waqf and individual share waqf.
\end{abstract}

Keywords: cash and share waqf, waqf implementation, literature study, legal study

Abstrak. Kajian Hukum dan Implementasi Wakaf Harta Bergerak di Indonesia: Wakaf Uang dan Saham. Wakaf adalah metode distribusi kekayaan non-pasar bersama zakat, infaq, dan shadaqah. Khususnya di Indonesia, praktik wakaf identik dengan sumbangan aset tetap, terutama tanah dan bangunan. Pemanfaatan sebagian besar aset wakaf di Indonesia tidak produktif secara ekonomi, seperti masjid dan pemakaman. Tujuan dari penelitian ini adalah untuk menganalisis kas dan share wakaf dan implementasinya. Penelitian ini diklasifikasikan sebagai tinjauan pustaka dengan pendekatan kualitatif. Metode Meta-synthesis diterapkan sebagai alat analisis. Hasilnya menunjukkan bahwa sebagian besar ulama Islam mengizinkan uang tunai dan saham untuk digunakan sebagai objek wakaf. Baik kas dan share wakaf dapat diimplementasikan ke dalam dua model. Wakaf uang tunai dapat diimplementasikan sebagai reksadana atau dikonversi menjadi aset tetap lainnya. Sedangkan pelaksanaan wakaf saham dapat dilakukan melalui wakaf korporat dan wakaf saham individu.

Keywords: wakaf tunai dan saham, implementasi wakaf, studi pustaka, studi hukum. 


\section{PENDAHULUAN}

Wakaf merupakan ibadah yang bersifat sosial, dimana seseorang menyerahkan hak milik atas suatu benda untuk dikelola dan dimanfaatkan hasilnya oleh publik ${ }^{1}$. Dalam proses wakaf terjadi peralihan sumber daya untuk tujuan produktif sehingga dapat dikatakan bahwa wakaf merupakan tindakan menabung dan berinvestasi². Tujuan pelaksanaan wakaf adalah pendistribusian kekayaan dan peningkatan taraf hidup masyarakat dalam jangka panjang melalui aspek non pemasukan, seperti penyediaan fasilitas umum, layanan kesehatan, dan lembaga pendidikan. ${ }^{3}$

Dalam undang-undang No. 41/2004 tentang wakaf telah diatur beberapa jenis harta yang dapat diwakafkan selain tanah dan bangunan, diantaranya uang dan saham. Namun demikian di Indonesia praktek wakaf masih identik dengan pemberian tanah dan bangunan yang digunakan untuk tempat ibadah atau pemakaman ${ }^{4}$ sebagaimana ditunjukkan dalam gambar 1 .

\section{Gambar 1. Pemanfaatan Tanah Wakaf di Indonesia}

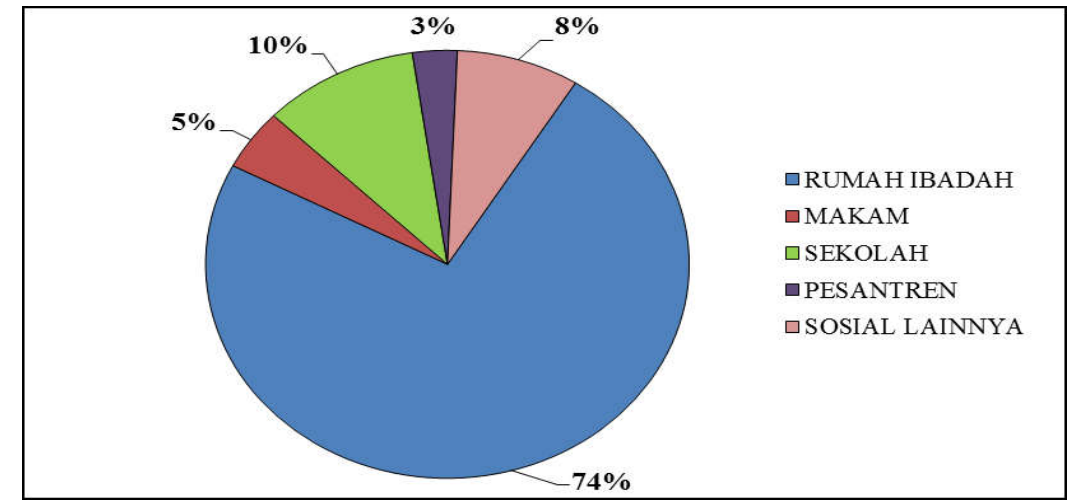

Sumber: Direktorat Pemberdayaan Wakaf Kemenag

Di beberapa negara lain seperti Singapura, Pakistan, dan Malaysia, mayoritas harta wakaf juga masih berupa tanah dan bangunan, meskipun pemanfaatan harta wakaf di negara-negara tersebut sudah lebih produktif secara ekonomi ${ }^{5}$. Jika merujuk pada hadits riwayat Muslim mengenai wakaf, sebetulnya tidak secara spesifik dinyatakan jenis harta yang dapat diwakafkan6. Hanya saja disebutkan bahwa hasil pengelolaan harta tersebut disedekahkan kepada yang membutuhkan. Pelaksanaan wakaf seharusnya dapat dilakukan dengan lebih inovatif, baik terkait jenis harta yang 
Girinda Mega, dkk.: Kajian Hukum dan...

diwakafkan maupun pengelolaannya. Kajian ini bertujuan untuk menelaah hukum dan implementasi penggunaan harta bergerak khususnya uang dan saham sebagai harta wakaf. Dengan demikian manfaat yang diterima oleh masyarakat akan lebih besar, mengingat tujuan awal wakaf sebagai alat distribusi kekayaan serta stimulus peningkatan taraf hidup masyarakat.

Kajian ini merupakan studi literatur yang mengidentifikasi, menginterpretasi, dan mengevaluasi semua sumber literatur terkait topik tertentu ${ }^{7}$. Analisa dalam kajian ini menggunakan metode meta-sintesis, yaitu proses mengintegrasi data untuk memperoleh teori-teori serta pemahaman-pemahaman baru yang lebih mendalam dan menyeluruh ${ }^{8}$. Adapun langkah-langkah yang ditempuh dalam penelitian studi literatur yaitu: ${ }^{2}$ (i) menyusun pertanyaan penelitian; (ii) mengumpulkan dan menyeleksi literatur terkait; (iii) mensintesa temuan; (iv) mengontrol kualitas sintesa; dan (v) menyusun laporan akhir.

\section{PEMBAHASAN}

\section{Kemunculan Wakaf Uang dan Saham}

Praktek wakaf di Indonesia hingga saat ini identik dengan penghibahan tanah dan bangunan. Pada dasarnya praktek penghibahan tanah untuk kepentingan umum bukan merupakan hal yang asing bagi masyarakat Indonesia, mengingat sebelum masuknya agama Islam praktek tersebut telah ditemukan di beberapa daerah. ${ }^{10}$

Jika merujuk pada hadits yang diriwayatkan oleh Muslim memang dikatakan bahwa Umar bin Khattab r.a menghibahkan tanah yang dimilikinya untuk dikelola sebagai kebun. ${ }^{11}$ Namun demikian substansi hadits tersebut bukanlah tentang proses penghibahan tanah, melainkan tentang inti kegiatan wakaf yaitu menahan pokok aset dan menyedekahkan hasilnya kepada yang memerlukan. ${ }^{12}$ Pendapat diperkuat dengan fakta tidak ditemukannya pertentangan dari mazhab-mazhab utama terkait substansi hadits tersebut. Sebagai contoh, Mazhab Syafii menyatakan bahwa yang terpenting adalah kekekalan manfaat harta wakaf, sehingga jika zat asli harta wakaf rusak dapat diganti dengan harta baru yang bisa memberi manfaat serupa.

Wakaf benda bergerak khususnya uang dan saham merupakan bentuk alternatif wakaf yang populer dikaji di masa modern. Bentuk wakaf uang pada dasarnya telah ada sejak abad ke-7 yaitu pada masa Imam Zuhri. Wakaf uang kembali populer di 
Islamiconomic: Jurnal Ekonomi Islam Vol.9 No.2 Juli - Desember 2018

masa modern pada awal tahun 2000-an melalui Social Islamic Bank Limited (SIBL) di Bangladesh yang diprakarsai oleh Abdul Mannan ${ }^{13}$ Salah satu produk SIBL adalah menghimpun dana wakaf dari masyarakat kemudian disalurkan sebagai modal usaha dan bantuan sosial. Sedangkan wakaf saham merupakan bentuk wakaf yang benarbenar baru dan belum banyak dikaji oleh cendekiawan Islam.

Kemunculan kajian mengenai wakaf benda bergerak disebabkan berbagai perubahan yang terjadi di masyarakat khususnya di bidang struktur sosial masyarakat dan teknologi. Disamping itu, hukum wakaf merupakan perkara muamalah yang memiliki prinsip dasar kebolehan semua hal kecuali ada dalil yang melarang14. Mekanisme wakaf jenis baru tersebut menjadi fokus riset para cendekiawan Islam, sebab mekanisme wakaf tradisional yang hanya memfokuskan kepada harta tak bergerak dipercaya tidak mampu memberikan manfaat secara maksimal kepada masyarakat. 15

\section{Perdebatan Hukum Pelaksanaan Wakaf Uang dan Saham}

Dalam pasal 16 ayat 3 UU No.41/2004 Tentang Wakaf disebutkan bahwa uang dan surat berharga termasuk ke dalam jenis harta bergerak. Diantara empat mazhab utama hanya mazhab Hanafi yang melarang praktek wakaf benda bergerak, sementara ketiga mazhab lainnya secara umum memperbolehkan. ${ }^{16}$ Mayoritas ulama mazhab Hanafi melarang praktek wakaf benda bergerak dengan alasan bahwa harta yang sah diwakafkan hanyalah benda bergerak. ${ }^{17}$ Hal tersebut disebabkan hanya benda tak bergerak, khususnya tanah dan bangunan, umur ekonomisnya sangat lama sehingga dianggap memiliki sifat kekal. Sementara benda bergerak akan lebih cepat mengalami kerusakan, sehingga dianggap tidak kekal.

Di sisi lain, mazhab Syafii, Hambali, dan Maliki memperbolehkan wakaf benda bergerak. Ketiga mazhab tersebut memiliki landasan bahwa kekekalan suatu harta wakaf tidak semata terletak pada zatnya saja, melainkan juga pada pada kekekalan manfaatnya. Sehingga jika suatu harta wakaf rusak zatnya, dapat diganti dengan harta baru yang mampu memberikan manfaat yang sama, meskipun benda tersebut bukanlah benda asli yang diwakafkan. Proses tersebut disebut sebagai proses istibdal. ${ }^{18}$ 
Girinda Mega, dkk.: Kajian Hukum dan...

Wakaf uang dan saham pada dasarnya dapat dihukumi sama dengan wakaf harta bergerak, yaitu boleh dilakukan berdasarkan pendapat mayoritas ulama. Namun demikian secara spesifik perdebatan hukum mengenai kebolehan wakaf uang dan saham berbeda dengan perdebatan hukum wakaf benda bergerak.

\section{Wakaf Uang}

Ulama yang melarang praktek wakaf uang antara lain Ibnu Qudamah, ${ }^{19}$ alSyirazi, dan Al-Bakri20. Alasan utama pelarangan praktek wakaf uang adalah aspek kekekalan zat harta wakaf. Hal tersebut bersumber dari hadits Rasulullah SAW yang memerintahkan Umar r.a untuk 'menahan pokoknya dan menyedekahkan hasilnya'. Sementara uang jika dimanfaatkan zatnya akan langsung habis, sehingga tidak kekal. Lebih lanjut Ibnu Qudamah juga berpendapat jika uang dimanfaatkan dengan tetap mempertahankan kekekalannya, artinya uang tersebut disewakan untuk memperoleh keuntungan. Padahal dalam konsep ekonomi Islam uang tidak boleh menghasilkan keuntungan kecuali diputar dalam sektor produksi.

Di sisi lain ulama yang memperbolehkan pelaksanaan wakaf uang diantaranya Imam Zuhri21, Abu Tsaur ${ }^{22}$, Imam Hanafi ${ }^{23}$, serta Asy-Syaibani24. Imam Zuhri berpendapat bahwa pemanfaatan wakaf uang yaitu dengan cara menjadikannya sebagai modal usaha dengan akad bagi hasil, yang kemudian keuntungannya disedekahkan. Sementara Imam Hanafi berpijak pada hukum 'urf dan pendapat Abdullah bin Masud, bahwasanya apa yang dipandang baik oleh seorang muslim maka akan dipandang baik pula oleh Allah. Maka selama wakaf uang membawa kebermanfaatan, tidak apa-apa dilakukan. Pendapat tersebut diperkuat dengan pendapat Asy-Syaibani yang menyatakan bahwa jika wakaf uang telah menjadi kebiasaan di suatu daerah maka tidak mengapa untuk dilanjutkan. Terkait aspek kekekalan harta wakaf, ulama yang memperbolehkan wakaf uang berpendapat bahwa kekekalan tidak hanya dapat dicapai melalui kekekalan zatnya melainkan dapat dicapai pula melalui kekekalan manfaat.

Di Indonesia wakaf uang telah dilegitimasi sebagai salah satu harta yang dapat diwakafkan. Legitimasi tersebut yaitu melalui fatwa MUI pada tanggal 11 Mei 2002, dimana MUI menyatakan kebolehan berwakaf dengan media uang. Fatwa MUI 
Islamiconomic: Jurnal Ekonomi Islam

Vol.9 No.2 Juli - Desember 2018

tersebut kemudian dijadikan acuan dalam pembuatan UU No. 41/2004 Tentang Wakaf, yang memperkuat kebolehan wakaf uang di Indonesia.

\section{Wakaf Saham}

Wakaf saham tergolong baru dalam lingkup kajian wakaf, sehingga belum ada pendapat khusus mengenai larangan maupun kebolehannya. Terkait saham itu sendiri, mayoritas ulama sepakat memperbolehkannya sebagai media investasi dengan catatan bidang usaha yang dijalankan dan akad kerjasamanya tidak melanggar syariat. ${ }^{25}$

Pada dasarnya terdapat keraguan mengenai investasi melalui media saham. Hal tersebut disebabkan oleh adanya peluang terjadinya gharar dan maysir dalam proses investasi saham. Gharar secara sederhana adalah segala tindakan yang mengandung ketidakjelasan ${ }^{26}$ sedangkan maysir merupakan tindakan perjudian, yaitu proses perolehan harta kekayaan dalam jumlah besar dan waktu yang singkat tanpa melakukan perkerjaan yang setimpal. ${ }^{27}$ Sesungguhnya memang tidak dapat disangkal bahwa kedua hal tersebut erat kaitannya dengan sistem keuangan modern, khususnya pada transaksi saham. Unsur gharar terdapat pada produk saham itu sendiri, dimana saham merupakan representasi aktivitas ekonomi perusahaan. Ketika seorang investor membeli saham tanpa mengetahui secara rinci kondisi perusahaan yang dibelinya, maka dapat dikatakan kegiatan tersebut sebagai jual beli gharar.28 Sementara unsur maysir datang dari ketidakpastian hasil yang akan diperoleh investor ketika ia memutuskan untuk berinvestasi melalui media saham. Dengan adanya gharar dan maysir tersebut, maka dapat dikatakan bahwa kegiatan berinvestasi melalui media saham tidak ubahnya sebagai sebuah perjudian.

Namun demikian, banyak pendapat yang menyatakan bahwa tindakan berinvestasi melalui media saham berbeda dengan kegiatan perjudian. Hal tersebut disebabkan fakta bahwa berinvestasi dalam pasar saham memerlukan keahlian khusus. Seorang investor akan mempertimbangkan berbagai macam hal sebelum memutuskan untuk berinvestasi pada sebuah perusahaan. Penilaian tersebut meliputi kekuatan dan kelemahan perusahaan, kondisi ekonomi masa kini, dan kondisi ekonomi di masa mendatang, ${ }^{29}$ sehingga tidak benar bahwa investasi melalui saham sama dengan proses perjudian. 
Girinda Mega, dkk.: Kajian Hukum dan...

Meskipun bersepakat mengenai kebolehan berinvestasi pada saham, masih ada perbedaan pendapat diantara para ulama mengenai jual beli saham khususnya di pasar sekunder. Diantara pendapat yang melarang transaksi perdagangan saham pada pasar sekunder yaitu dari Ash-Shawi dan Muslih, ${ }^{30}$ An-Nabhani, ${ }^{31}$ serta Abduh. ${ }^{32}$ Alasan larangan transaksi saham tersebut adalah tidak adanya unsur serah terima yang nyata dalam transaksi serta status saham sebagai barang yang tidak riil, sehingga perdagangan saham mengandung unsur ketidakjelasan dalam transaksinya. Lebih lanjut harga saham mencerminkan nilai total perusahaan termasuk utang sehingga perdagangan saham juga berarti memperdagangkan utang, padahal jual beli utang dilarang dalam Islam.

Sedangkan pendapat yang memperbolehkan jual beli saham di pasar sekunder diantaranya berasal dari Qardhawi, ${ }^{33}$ Shihab, ${ }^{34}$ serta Zuhaili. ${ }^{35}$ Qardhawi dan Zuhaili menegaskan kebolehan transaksi dilakukan selama bidang usaha tidak melanggar aturan syariat. Sedangkan Shihab berpendapat bahwa bukti transaksi sudah cukup mewakili jual beli saham karena memang barangnya tidak bisa diserahterimakan. Fatwa No. 80 DSN-MUI/III/2011 juga menegaskan kebolehan perdagangan efek, namun harus disertai dengan kewaspadaan penuh.

Terkait berwakaf melalui media saham, undang-undang wakaf Indonesia menyatakan bahwa saham tergolong ke dalam benda bergerak yang boleh diwakafkan. Sementara mayoritas ulama khususnya dari mazhab Maliki, Syafi'i, dan Hambali memperbolehkan pelaksanaan wakaf benda bergerak. Maka dari itu dapat disimpulkan bahwa hukum wakaf saham disamakan dengan hukum wakaf harta bergerak lainnya yaitu boleh dilakukan.

\section{Implementasi Wakaf Uang dan Saham}

Pelaksanaan wakaf uang dan saham berbeda dengan wakaf tanah dan bangunan. Hal tersebut disebabkan oleh dua hal yaitu: (i) adanya aspek kekekalan yang harus dipenuhi; dan (ii) bentuk uang dan saham yang tidak bisa dimanfaatkan secara langsung. Dengan demikian perlu model khusus dalam mengimplementasikan uang dan saham sebagai aset wakaf. 
Islamiconomic: Jurnal Ekonomi Islam

Vol.9 No.2 Juli - Desember 2018

Wakaf Uang

Ketentuan umum pengelolaan wakaf uang di Indonesia terdapat pada Peraturan Pemerintah No. 41/2004 Tentang Pelaksanaan UU No.41/2004, khususnya dalam pasal 22 hingga 27. Berikut ringkasan ketentuan pelaksanaan wakaf uang di Indonesia:

1. Wakaf uang hanya bisa dilakukan dengan mata uang rupiah. Adapun mata uang asing yang akan diwakafkan harus dikonversikan terlebih dahulu ke dalam mata uang rupiah.

2. Wakaf uang akan dikelola oleh Lembaga Keuangan Syariah Penerima Wakaf Uang (LKS-PWU) yang harus memenuhi persyaratan sebagai berikut:

a. Menyampaikan permohonan tertulis kepada Menteri

b. Melampirkan dokumen Anggaran Dasar dan dokumen pengesahannya sebagai badan hukum

c. Memiliki kantor operasional di dalam wilayah Republik Indonesia

d. Bergerak di bidang keuangan syariah

e. Memiliki fungsi menerima titipan (wadiah); dan

f. Direkomendasikan oleh Badan Wakaf Indonesia (BWI)

3. Tugas-tugas yang harus dilakukan LKS-PWU sebagai lembaga pengelola wakaf yaitu:

a. Mengumumkan keberadaannya sebagai LKS-PWU kepada publik

b. Menyediakan blangko Sertifikat Wakaf Uang (SWU)

c. Menerima wakaf uang secara tunai dari wakif atas nama nadzir

d. Menempatkan uang wakaf ke dalam rekening titipan atas nama nadzir

e. Menerima pernyataan kehendak wakif yang dituangkan secara tertulis

f. Menerbitkan SWU serta menyerahkan sertifikat tersebut pada wakif dan menyerahkan tembusan pada nadzir yang ditunjuk wakif

g. Mendaftarkan wakaf uang kepada menteri atas nama nadzir

Pada dasarnya pemanfaatan wakaf uang dilakukan dengan cara menginvestasikan uang tunai baik ke dalam sektor riil maupun sektor moneter. Secara umum hal tersebut serupa dengan reksadana, yaitu uang dikumpulkan oleh manajer investasi untuk diusahakan. Dalam hal wakaf uang, nadzir berperan sebagai 180 
Girinda Mega, dkk.: Kajian Hukum dan...

manajer investasi yang mengelola uang wakaf. Uang yang terkumpul dapat dimanfaatkan dengan dua cara yaitu: pertama, dirubah ke dalam bentuk aset tetap; atau kedua, diinvestasikan ke dalam instrumen keuangan dan akad kerjasama.

Pemanfaatan wakaf uang model pertama misalnya dengan membeli tanah atau bangunan untuk dikelola sebagai aset wakaf. Konversi ke dalam aset tetap akan menjamin aspek kekekalan manfaat dan kekelan zat wakaf. Aset tetap yang telah dibeli dengan uang wakaf, selanjutnya dikelola oleh nadzir sebagaimana wakaf pada umumnya. Pengelolaan tersebut seharusnya dilakukan sebaik mungkin agar tidak terjebak pada model-model pengelolaan wakaf tradisional seperti pemakaman dan masjid. Gambar 2 mengilustrasikan model pengelolaan wakaf uang melalui konversi pada aset tetap.

\section{Gambar 2. Pengelolaan Wakaf Uang Model Aset Tetap}

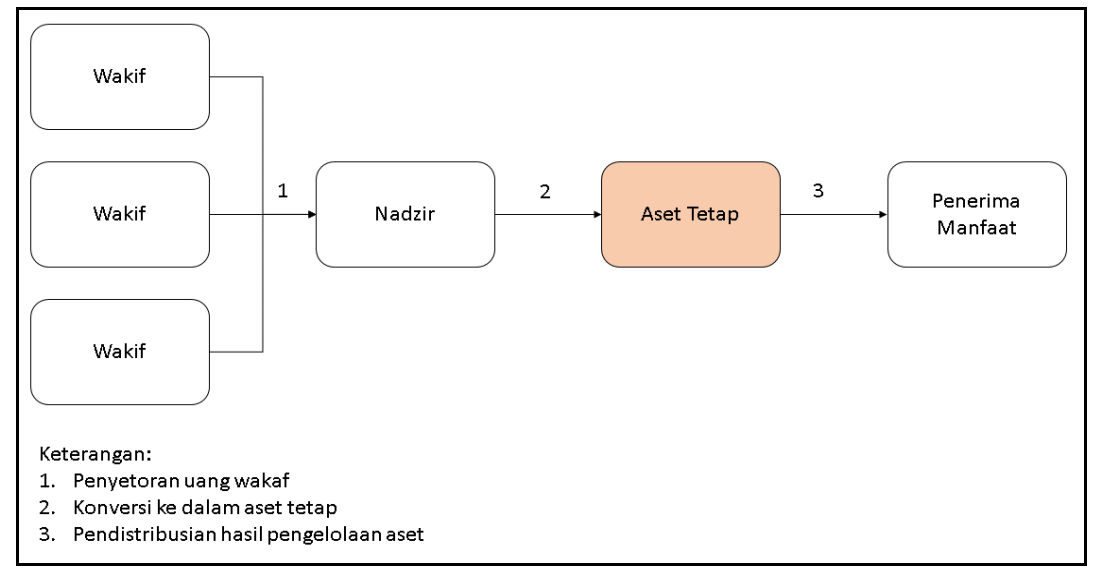

Sumber: Ilustrasi Penulis (2018)

Hendaknya pengelolaan aset wakaf dilakukan sedemikian rupa sehingga mampu memberikan manfaat ekonomi bagi masyarakat. Sebagai contoh misalnya bagunan yang dibeli dengan uang wakaf dapat dikelola sebagai pertokoan dan bentuk-bentuk usaha lain. Jika nadzir belum memiliki kecakapan untuk mengelola sendiri, maka gedung tersebut dapat disewakan sebagai perkantoran dan kegunaan lainnya selama tidak melanggar syariat.

Sebagian ulama berpendapat bahwa proses konversi wakaf uang ke dalam bentuk aset tetap menyebabkan status wakaf uang gugur dan menjadi wakaf biasa. ${ }^{36}$ 
Islamiconomic: Jurnal Ekonomi Islam Vol.9 No.2 Juli - Desember 2018

Namun demikian hal tersebut hanya merupakan istilah teknis saja. Pada substansinya wakaf tersebut tetaplah berasal dari uang wakaf yang telah dikumpulkan nadzir.

Pemanfaatan wakaf uang model kedua yaitu uang wakaf dapat diinvestasikan ke dalam instrumen-instrumen keuangan seperti saham, reksadana, maupun deposito agar menghasilkan keuntungan. Selain diinvestasikan melalui instrumen keuangan, wakaf uang juga dapat dikelola oleh nadzir melalui akad-akad kerjasama. Dalam hal ini nadzir berlaku sebagai shahibul maal yang melakukan kerja sama dengan mudharib. Gambar 3 mengilustrasikan model pengelolaan wakaf uang melalui konversi pada instrumen keuangan.

\section{Gambar 3. Pengelolaan Wakaf Uang Model Instrumen Keuangan}

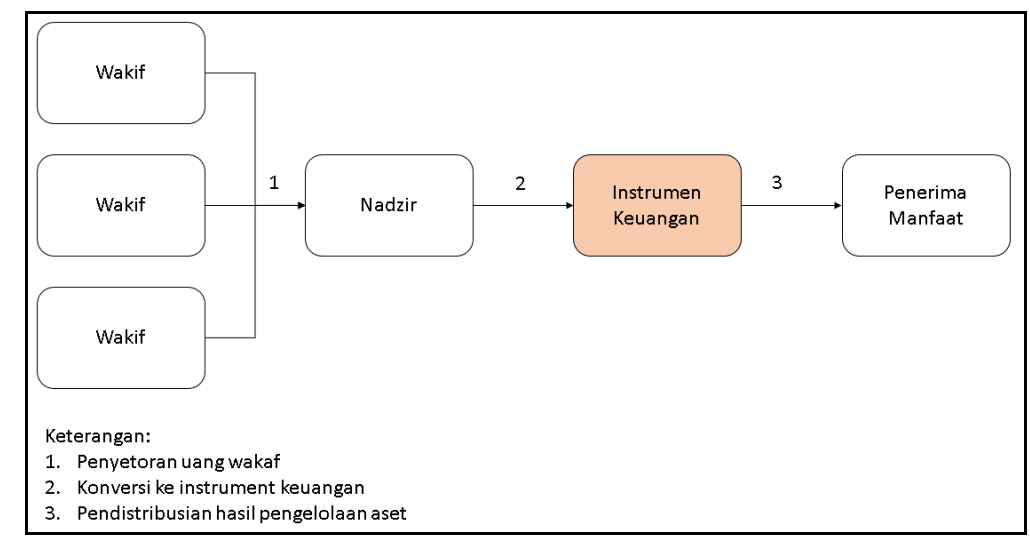

Sumber: Ilustrasi Penulis (2018)

Namun demikian, pengelolaan tersebut menuntut nadzir untuk memiliki kecakapan yang lebih. Selain harus memiliki kecerdasan dalam mengelola aset, nadzir juga harus memahami aturan-aturan akad serta kecakapan dalam berbisnis. Dengan demikian akan mengurangi resiko berkurangnya harta wakaf karena kecurangan yang terjadi dalam akad.

\section{Wakaf Saham}

Konsep pengelolaan wakaf saham pada dasarnya serupa dengan wakaf uang. Hal tersebut disebabkan objek wakaf keduanya sama yaitu uang. Hanya saja sumber uang pada wakaf saham secara spesifik berasal pengelolaan saham. Saat ini terdapat dua model pengelolaan wakaf saham, yaitu wakaf korporasi dan wakaf saham 
Girinda Mega, dkk.: Kajian Hukum dan...

perorangan. ${ }^{37}$ Lebih lanjut wakaf saham perorangan dapat dibagi lagi menjadi jenis berdasarkan objek yang diwakafkan, yaitu yang berasal dari keuntungan penjualan wakaf (capital gain) dan yang berasal dari keuntungan pengelolaan saham.

Dalam model wakaf korporasi, sebuah perusahaan didirikan untuk mengelola harta wakaf. Perusahaan wakaf tersebut didirikan oleh lembaga non profit atau oleh sebuah perusahaan induk sebagai anak perusahaan. Harta yang dikelola utamanya berasal dari masyarakat yang 'membeli' sertifikat wakaf dari perusahaan tersebut ${ }^{38}$. Namun demikian tidak menutup kemungkinan terdapat sumber wakaf lain yang dikelola oleh perusahaan wakaf. Sebagai contoh, dalam hal perusahaan wakaf yang berstatus sebagai anak perusahaan, maka perusahaan wakaf juga mengelola dana CSR milik perusahaan induk disamping dana wakaf yang dihimpun. Hal tersebut sebagaimana yang terjadi di Turki ${ }^{39}$ pada Koc Holding Company dan di Malaysia pada Jcorp. ${ }^{40}$

Pemanfaatan wakaf uang yang telah terkumpul dapat disesuaikan dengan keinginan wakif atau disesuaikan dengan kebijakan perusahaan induk. Sebagai contoh, yayasan Koc mengelola wakafnya untuk membiayai proyek kemanusiaan di bidang pendidikan, riset sejarah, seni, dan kesehatan. Sedangkan JCorp memfokuskan penggunaan harta wakaf untuk pengembangan SDM, kesehatan, serta pembangunan dan program kerja masjid.

Sedangkan model wakaf saham perorangan merupakan model wakaf yang bersumber dari saham yang dimiliki perseorangan. Hogan membagi model wakaf ini menjadi dua jenis berdasarkan objek wakafnya. Objek wakaf jenis pertama adalah keuntungan yang diperoleh investor dari perdagangan efek. Dalam wakaf jenis ini, Anggota Bursa $(\mathrm{AB})$ menjadi fasilitator yang menjembatani investor dan nadzir.

Keuntungan yang diperoleh investor dari perdagangan efek akan dipotong sebagian oleh $\mathrm{AB}$ sesuai dengan perjanjian, kemudian diserahkan kepada nadzir untuk dikelola. Sementara objek wakaf jenis kedua adalah saham milik investor. Dalam wakaf jenis ini investor menyerahkan sejumlah saham yang dimilikinya kepada manajer investasi untuk dirawat dan dikelola agar menghasilkan keuntungan. Keuntungan yang dihasilkan, selanjutnya diserahkan kepada nadzir untuk dikelola. Secara ringkas, gambar 4 menunjukkan alur pengelolaan wakaf saham perorangan. 


\section{Gambar 4. Dua Model Pengelolaan Wakaf Saham Perorangan}

\section{A: Model 1}

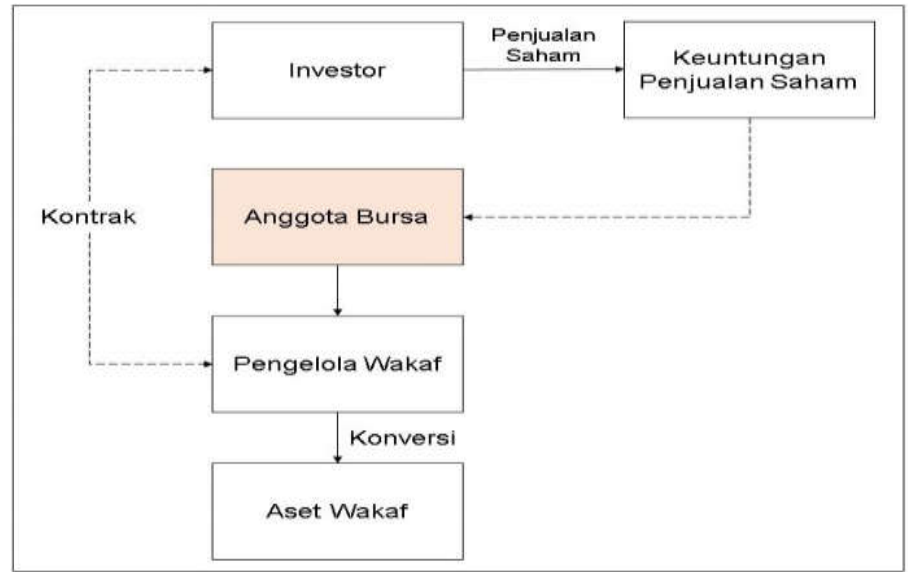

\section{B: Model 2}

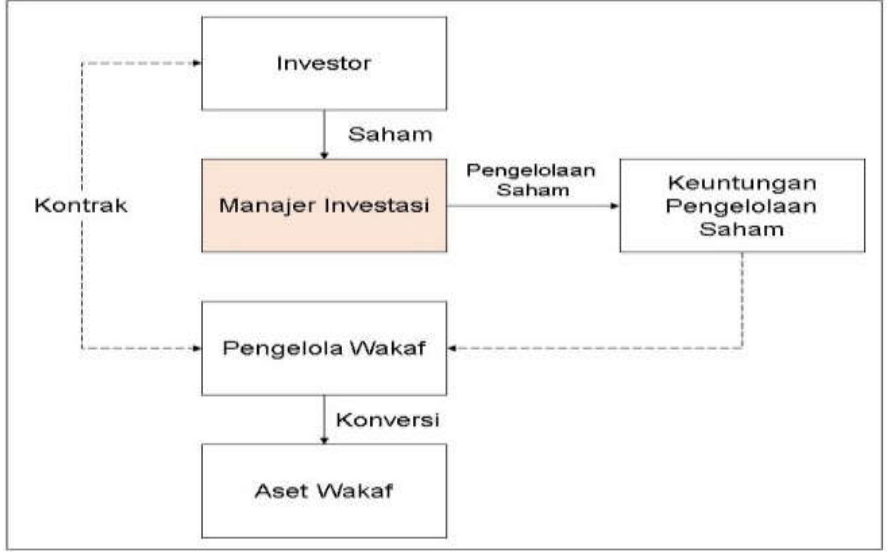

Sumber: Dimodifikasi dari Hogan (2016)

\section{Hambatan Pelaksanaan Wakaf Uang dan Saham}

Hambatan utama pelaksanaan wakaf uang dan saham adalah pola pikir masyarakat mengenai kebolehan berwakaf melalui aset selain tanah dan bangunan. ${ }^{41}$ Meskipun mayoritas ulama telah memperbolehkan dan telah diatur di dalam undangundang, namun hingga saat ini wakaf selain tanah dan bangunan masih rendah. Wakaf uang dan saham dapat dikatakan masih baru, sehingga masyarakat mungkin masih ragu akan kebolehannya dan memilih untuk berhati-hati. 
Girinda Mega, dkk.: Kajian Hukum dan...

Di sisi lain menemukan model pengelolaan wakaf uang dan saham yang tepat juga bukan perkara mudah. Jika dana wakaf dikelola sebagai investasi, terdapat kemungkinan harta wakaf menjadi berkurang nilainya akibat siklus pasar. Pemanfaatan dana wakaf melalui konversi ke dalam aset tetap juga harus berhati-hati agar tidak terjebak ke dalam pemanfaatan yang secara ekonomi kurang produktif seperti tempat ibadah dan sekolah.

Lebih lanjut, hingga saat ini belum ada peraturan resmi yang mengatur mengenai mekanisme wakaf uang dan saham. Undang-undang yang ada saat ini hanya mengatur secara normatif mengenai hukum-hukum pelaksanaannya. Khususnya mengenai wakaf saham yang memerlukan aturan rinci dalam kaitannya dengan kondisi pasar saham. Misalnya bagaimana sistem pencatatan saham yang dijadikan sebagai objek wakaf. Dalam hal ini Otoritas Jasa Keuangan belum menerbitkan peraturan maupun petunjuk teknis tertentu.

\section{KESIMPULAN}

Berdasarkan pembahasan di atas dapat disimpulkan bahwa uang dan saham dapat diwakafkan. Mayoritas ulama telah memperbolehkan berwakaf melalui uang dan saham, dengan berdasar pada prinsip muamalah yaitu semua hal diperbolehkan kecuali ada dalil yang melarang. Hadits yang menjadi dasar hukum wakaf hanya menjelaskan tentang inti kegiatan wakaf, sedangkan detail pelaksanaannya merupakan hasil ijtihad dari para ulama. Secara umum model pengelolaan wakaf uang dan wakaf saham sama yaitu mengumpulkan dana untuk kemudian dikonversikan ke dalam bentuk aset tetap atau diinvestasikan ke dalam instrumen keuangan. Hanya saja dalam pembahasan wakaf saham, sumber dana wakaf secara spesifik berasal dari saham dan pengelolaannya. Adapun hambatan utama dari implementasi wakaf uang dan saham adalah pola pikir masyarakat yang masih terpaku pada jenis aset dan model pengelolaan wakaf tradisional.

\section{PUSTAKA ACUAN}

Alam, Md. Mahmudul; Akbar, Chowdury Shahed; Shahriar, Shawon Muhammad; and Elahi, Mohammad Monzur. The Islamic Sharia Principles in Stock Market. Qualitative Research in Financial Market Vol. 9 Issue 2, pp. 132-146. (2017) 
Islamiconomic: Jurnal Ekonomi Islam

Vol.9 No.2 Juli - Desember 2018

$\overline{\text { Al-Amany, Mikail (ed.), Siddiqi, Abdul Hamid (terj). Shahih Muslim (versi digital). }}$ Diakses pada

tautan: http://d1.islamhouse.com/data/en/ih_books/single/en_Sahih_Muslim.pdf pada tanggal 5 Maret 2017 (2009)

Al-Barwary, Syaban Muhammad, Bursa Saham Menurut Pandangan Islam, (Kuala Lumpur: Berlian Production, 2007)

Al-Kabisi, Muhammad Abid Abdullah. Hukum Wakaf. (Jakarta: Ilman Press, 2004)

An-Nabhani, Taqiyudin. (2004). An-Nizam Al-Iqtisadi fil Islam. Beirut: Darul Ummah, 2004

Ash-Shawi, Shalah; Muslih, Abdullah. Fikih Ekonomi Keuangan Islam. (Jakarta: Pustaka Darul Haq, 2017)

Athoillah, H.M. Hukum Wakaf. (Bandung: Penerbit Yrama Widya, 2014)

Budiman, Mochammad Arif \& Kusuma, Dimas Bagus W. (2011). The Economic Significance of Waqf: A Macro Perspective. Presented on The $8^{\text {th }}$ International Conference on Tawhidi Methodology Applied to Islamic Microenterprise Development. Diakses pada tautan: https://papers.ssrn.com/sol3/papers.cfm?abstract_id=1844606 pada tanggal 5 Maret (2017)

Cizakca, Murat. Waqf in History and Its Implications for Modern Islamic Economies. Essential Readings in Contemporary Waqf Issues. (Kuala Lumpur: CERT, 2011)

Dirjen Bimas Islam. Paradigma Baru Wakaf di Indonesia. (Jakarta: Kemenag RI, 2013)

Fahruroji dan Arifin, Jaenal. Pengembangan Harta Wakaf di Singapura. Equilibrium Vol 3 No. 1, (2015)

Hart, Chris. Doing a Literature Review: Releasing the Social Science Research Imagination. (London: Sage Publications, 1998)

Hassan, M. Kabir. Faith Based Ethical Investing: The Case of Dow Jones Islamic Indexes. Networks Financial Institute Working Paper No. 2011-WP-06, (2011)

Hogan, Nicky. Wakaf Saham Alternatif Model Wakaf Produktif. Silaturahmi Kerja Nasional Masyarakat Ekonomi Syariah (Silaknas MES), diselenggarakan oleh Masyarakat Ekonomi Syariah pada 18-19 November 2016 di Jakarta, (2016)

Ibnu Qudamah. Al-Mughni wa Syarhul kabir. (Beirut: Darul Alamul Kutub.1997) 
Girinda Mega, dkk.: Kajian Hukum dan...

Ibrahim, Dahlia, and Ibrahim, Haslindar. Revival of Waqf Properties in Malaysia. Paper proceeding of the 5th Islamic Economics System Conference (iECONS 2013), "Sustainable Development through the Islamic Economics System", diselenggarakan oleh Faculty Economics And Muamalat, Universiti Sains Islam Malaysia, Berjaya Times Square Hotel, Kuala Lumpur, 4-5th September 2013. (2013)

Isfandiar, Ali Amin. Tinjauan Fiqih Muamalat dan Hukum Nasional tentang Wakaf di Indonesia. La Riba Jurnal Ekonomi Islam, Vol. 2 No. 1, (2008)

Ismail, Abdul Ghoffar; Possumah, Bayu Taufiq. (2014). Waqf as Economic Matters but Being Left Out as Policy Tools. IRTI Working Paper Series No. 1436-01. Jeddah: Islamic Research and Training Institute, (2014)

Kahf, Monzer. Manajemen Wakaf Produktif. (Jakarta: Khalifa, 2005)

Khairi, Khairil Faizal. Human and Economic Development Through Share Waqf (Waqf Corporate: The Case of GLCs in Malaysia. Life Science Journal Vol. 11 No. X, (2014)

Masyita, Dian; Tasrif, Muhammad; \& Telaga; Abdi Suryadinata. A Dynamic Model for Cash Waqf Management as One of the Alternative Instruments for the Poverty Alleviation in Indonesia. The $23^{\text {rd }}$ International Conference of The System Dynamics Society. Boston: Sloan School of Management, Massachussets Institute of Technology, (2005)

Mohammad, Mohammad Tahir Sabit \& Iman, Abdul Hamid M. Obstacles of the Current Concept of Waqf to the Development of Waqf Properties and the Recommended Alternative. Malaysian Journal of Real Estate, Vol.1 (1), (2006)

Mohsin, Magda Ismail. What We can Do with Waqf Properties. (INCEIF, 2014)

Mohsin, Magda Ismail; Dafterdar, Hisham; Cizakca, Murat, et al. Financing the Development of Old Waqf Properties. (New York: Palgrave Macmillan, 2016)

Mujieb, M. Abdul dkk. Kamus Istilah Fiqih, cet. III, (Jakarta: Pustaka Firdaus., 2002)

Perry, A. \& Hammond, N. Systematic Reviews: The Experience of a PhD Student. Psychology Learning and Teaching, Vol. 2 (1), (2002)

Qardhawi, Yusuf. Hukum Zakat. (Bogor: Litera Antar Nusa, 1999) 
Islamiconomic: Jurnal Ekonomi Islam Vol.9 No.2 Juli - Desember 2018

Ramli, Asharaf Mohd; Jalil, Abdullah. Corporate Waqf Model and Its Distinctive Features: The Future of Islamic Philanthropy. Dipresentasikan pada Worlds Universities Islamic Philanthropy Conference di Kuala Lumpur, Malaysia, (2013)

Rozalinda. Fiqih Muamalah dan Aplikasinya pada Perbankan Syariah. (Padang: Hayfa Press, 2005)

Salamon, HB; Ebrahimi, Mansoureh; Yusoff, Kamaruzaman. Speculation: The Islamic Perspective; A Study on Al-Maisir (Gambling). Mediterranean Journal of Social Science. Vol. 6 No. 1, (2015)

Shihab, Quraish. Kumpulan Tanya Jawab. (Jakarta: Penerbit Republika, 2004)

Shirazi, N.S., Obaidullah, M., Haneef, M.A., Integration of Waqf and Islamic Microfinance for Poverty Reduction: Case of Pakistan. IRTI Working Paper Series 39 No. 1436-05, (2015)

Siswanto. (2010). Systematic Review Sebagai Metode Penelitian untuk Mensintesis Hasil-Hasil Penelitian. Buletin Penelitian Sistem Kesehatan Vol. 13 No. 4, (2010)

Sulistiani, Siska Lis, Pembaruan Hukum Wakaf di Indonesia. (Bandung: Refika Aditama, 2017)

Uddin, Akhter, Principle of Islamic Finance: Prohibition of Riba, Gharar, and Maysir. MPRA Working Paper No. 67711, 2015

Zein, Satria Effendi, Problematika Hukum Keluarga Islam Kontemporer (Jakarta: Kencana, 2004)

Zuhaili, Wahbah, Al-Fiqh al-Islami wa 'Adilatuhu (Damaskus: Darul Fikri al-Mu'ashir, 2008)

Tageldin, Seif I. The Stock Exchange from an Islamic Perspective. Journal of King Abdul Azis University: Islamic Economics. Vol. 8 No.1 pp. 29-48. , (1996)

\section{Catatan Akhir:}

\footnotetext{
${ }^{1}$ Mujieb, M. Abdul dkk. (2002), Kamus Istilah Fiqih, cet. III, Jakarta: Pustaka Firdaus

Zein, Satria Effendi. (2004). Problematika Hukum Keluarga Islam Kontemporer. Jakarta: Kencana

2 Budiman, Mochammad Arif \& Kusuma, Dimas Bagus W. (2011). The Economic Significance of Waqf: A Macro Perspective.

3 Mohammad, Mohammad Tahir Sabit \& Iman, Abdul Hamid M. (2006). Obstacles of the Current Concept of Waqf to the Development of Waqf Properties and the Recommended Alternative. Malaysian Journal of Real Estate, Vol.1 (1)

Ismail, Abdul Ghoffar; Possumah, Bayu Taufiq. (2014). Waqf as Economic Matters but Being Left Out as Policy Tools. IRTI Working Paper Series No. 1436-01. Jeddah: Islamic Research and Training Institute.
} 
Girinda Mega, dkk.: Kajian Hukum dan...

${ }^{4}$ Isfandiar, Ali Amin. 2008. Tinjauan Fiqih Muamalat dan Hukum Nasional tentang Wakaf di Indonesia. La Riba Jurnal Ekonomi Islam, Vol. 2 No. 1

${ }^{5}$ Mohsin, Magda Ismail. (2014). What We can Do with Waqf Properties. INCEIF

Mohsin, Magda Ismail; Dafterdar, Hisham; Cizakca, Murat, et al. (2016). Financing the Development of Old Waqf Properties. New York: Palgrave Macmillan;

Shirazi, N.S., Obaidullah, M., Haneef, M.A. (2015). Integration of Waqf and Islamic Microfinance for Poverty Reduction: Case of Pakistan. IRTI Working Paper Series 39 No. 1436-05

${ }^{6}$ Al-Amany, Mikail (ed.), Siddiqi, Abdul Hamid (terj). (2009). Shahih Muslim

${ }^{7}$ Hart, Chris. (1998). Doing a Literature Review: Releasing the Social Science Research Imagination. London: Sage Publications;

Kitchenham, Barbara. (2004). Procedures for Performing Systematic Reviews. Eversleigh: Keele University

8 Perry, A. \& Hammond, N. (2002). Systematic Reviews: The Experience of a PhD Student. Psychology Learning and Teaching, Vol. 2 (1).

${ }^{9}$ Siswanto. (2010). Systematic Review Sebagai Metode Penelitian untuk Mensintesis Hasil-Hasil Penelitian. Buletin Penelitian Sistem Kesehatan Vol. 13 No. 4.

10 Sulistiani, Siska Lis. (2017). Pembaruan Hukum Wakaf di Indonesia. Bandung: Refika Aditama

11 Al-Amany (2009), op.cit

12 Sulistiani, (2017), op.cit

13 Masyita, Dian; Tasrif, Muhammad; \& Telaga; Abdi Suryadinata. (2005). A Dynamic Model for Cash Waqf Management as One of the Alternative Instruments for the Poverty Alleviation in Indonesia. The 23rd International Conference of The System Dynamics Society. Boston: Sloan School of Management, Massachussets Institute of Technology

14 Rozalinda. (2005). Fiqih Muamalah dan Aplikasinya pada Perbankan Syariah. Padang: Hayfa Press

15 Ibrahim, Dahlia, and Ibrahim, Haslindar. (2013). Revival of Waqf Properties in Malaysia. Paper proceeding of the 5th Islamic Economics System Conference (iECONS 2013), "Sustainable Development through the Islamic Economics System", diselenggarakan oleh Faculty Economics And Muamalat, Universiti Sains Islam Malaysia, Berjaya Times Square Hotel, Kuala Lumpur, 4-5th September 2013.

${ }^{16}$ Al-Kabisi, Muhammad Abid Abdullah. (2004). Hukum Wakaf. Jakarta: Ilman Press;

Athoillah, H.M. (2014). Hukum Wakaf. Bandung: Penerbit Yrama Widya

17 Dirjen Bimas Islam. (2013). Paradigma Baru Wakaf di Indonesia. Jakarta: Kemenag RI

18 Fahruroji dan Arifin, Jaenal. (2015). Pengembangan Harta Wakaf di Singapura. Equilibrium Vol 3 No. 1

19 Ibnu Qudamah. (1997). Al-Mughni wa Syarhul kabir. Beirut: Darul Alamul Kutub

${ }^{20}$ Athoillah, (2014), op.cit

21 Isfandiar, (2008); op.cit

Athoillah, (2014) op.cit

22 Al-Mawardi, Mahmud Mathraji. 1994. Al-Hawi al-Kabir. Beirut: Darul Fikr

${ }^{23}$ Zuhaili, Wahbah. (2008). Al-Fiqh al-Islami wa 'Adilatuhu. Damaskus: Darul Fikri al-Mu'ashir

${ }^{24}$ Sulistiani (2017) op.cit

25 Hassan (2011); Uddin (2015); Alam (2017)

${ }^{26}$ Mihajat, Muhammad Iman S. (2016). Contemporary Practice of Riba', Gharar, and Maysir in Islamic Banking and Finance. International Journal of Islamic Management and Business Vol. 2 No. 2

27 Al-Qurtubi (2010). Al-Jami' Li Ahkamul Quran, Vol. 2. Cairo: Darul Hadits.

28 Tageldin, Seif I. (1996). The Stock Exchange from an Islamic Perspective. Journal of King Abdul Azis University: Islamic Economics. Vol. 8 No.1 pp. 29-48.

29 Salamon, HB; Ebrahimi, Mansoureh; Yusoff, Kamaruzaman. (2015). Speculation: The Islamic Perspective; A Study on Al-Maisir (Gambling). Mediterranean Journal of Social Science. Vol. 6 No. 1

30 Ash-Shawi, Shalah; Muslih, Abdullah. 2017. Fikih Ekonomi Keuangan Islam. Jakarta: Pustaka Darul Haq

${ }^{31}$ An-Nabhani, Taqiyudin. (2004). An-Nizam Al-Iqtisadi fil Islam. Beirut: Darul Ummah

32 Al-Barwary, Syaban Muhammad. (2007). Bursa Saham Menurut Pandangan Islam. Kuala Lumpur: Berlian Production

33 Qardhawi, Yusuf. (1999). Hukum Zakat. Bogor: Litera Antar Nusa

${ }^{34}$ Shihab, Quraish. (2004). Kumpulan Tanya Jawab. Jakarta: Penerbit Republika 
Islamiconomic: Jurnal Ekonomi Islam

Vol.9 No.2 Juli - Desember 2018

35 Zuhaili (2008), op.cit

${ }^{36}$ Kahf, Monzer. (2005). Manajemen Wakaf Produktif. Jakarta: Khalifa;

Athoillah (2014), op.cit

${ }^{37}$ Hogan, Nicky. (2016). Wakaf Saham Alternatif Model Wakaf Produktif. Silaturahmi Kerja Nasional Masyarakat Ekonomi Syariah (Silaknas MES), diselenggarakan oleh Masyarakat Ekonomi Syariah pada 18-19 November 2016 di Jakarta

38 Khairi, Khairil Faizal. (2014). Human and Economic Development Through Share Waqf (Waqf Corporate: The Case of GLCs in Malaysia. Life Science Journal Vol. 11 No. X

${ }^{39}$ Cizakca, Murat. (2011). Waqf in History and Its Implications for Modern Islamic Economies. Essential Readings in Contemporary Waqf Issues. Kuala Lumpur: CERT

${ }^{40}$ Ramli, Asharaf Mohd; Jalil, Abdullah. (2013). Corporate Waqf Model and Its Distinctive Features: The Future of Islamic Philanthropy. Dipresentasikan pada Worlds Universities Islamic Philanthropy Conference di Kuala Lumpur, Malaysia;

Khairi (2014) op.cit

41 Isfandiar (2008), op.cit 